Revista Iberoamericana, Vol. LXXI, Núm. 213, Octubre-Diciembre 2005, 1109-1119

\title{
GÜEMES Y LOS DE ABAJO: FABRICACIÓN Y ALCANCE DEL HEROISMO EN LA GUERRA GAUCHA
}

\author{
POR \\ NATHALIE FÜRSTENBERGER \\ Université de Valenciennes et du Hainaut-Cambrésis
}

Cada vez que Leopoldo Lugones quiere ensalzar la identidad argentina, aprovechándose de eventos conmemorativos, acude al héroe. Recurre muy a menudo a la leyenda de la guerra de Troya y el retorno de Ulises a su patria para defender un proyecto ético de alcance nacional. Es el caso de los ensayos Prometeo (1910) y El payador (1916), publicados con motivo del Centenario de la Revolución de Mayo, así como de los Estudios helénicos (1924), obra en la que recopiló las conferencias que había leído en 1916 para celebrar el aniversario de la independencia.

En realidad, y a pesar de su título, los Estudios helénicos solo recogen glosas y comentarios eruditos de unas traducciones escogidas de la Ilíada y la Odisea. Poco conocida, esta obra volvió a ser publicada en las Obras poéticas completas, bajo una forma expurgada. ${ }^{1}$ Desaparecieron de esta edición todos los “estudios helénicos” que le habían permitido a Lugones no solo recalcar el valor poético de los mitos, sino también proponer a sus lectores una interpretación muy personal de los valores morales homéricos, haciendo coexistir antiguos héroes míticos con paladines de la corte de Carlomagno o con caballeros de la Mesa Redonda.

Un rápido examen del conjunto de la obra de Leopoldo Lugones muestra que, conforme se afianza el nacionalismo conservador del autor, la figura heroica del gaucho -o mejor dicho la del caudillo gaucho-se convierte en un héroe mítico clásico, totalmente desvinculado de la realidad nacional. En este proceso, la publicación de El payador marca un hito: las teorías que desarrolló Lugones para rescatar el Martín Fierro, arrancándolo del circuito menospreciado de la cultura popular, no dejaron de escamotearlo, mediante extrapolaciones literarias que hacían de la obra una epopeya nacional y del gaucho -parangón de la “argentinidad”- una reencarnación del héroe griego.

En los Estudios helénicos, Lugones echa de menos el éxito que tuvieron sus conferencias sobre el poema de Hernández (1913), explicando que había visto entonces

\footnotetext{
${ }^{1}$ En esta obra Pedro Obligado recoge en un solo capítulo todos los cantos de la Ilíada y de la Odisea traducidos por Lugones. De modo que en vez de publicar las versiones originales de obras tales como Estudios helénicos, Nuevos Estudios helénicos o El ejército de la Ilíada, de donde sacó dichos fragmentos, las desnaturaliza restaurando "el orden [homérico] de los distintos cantos de ambos poemas”. Se justifica explicando que solo le importa dar cuenta al público lector de la calidad poética de la labor lugoniana (1308-10).
} 
en la afición a la poesía y a la belleza de su público una antigua virtud ateniense. Recuerda sus pasadas conclusiones en los siguientes términos:

Yo declaré a Martín Fierro héroe de la grande épica que constituyen las Ilíadas y los Romanceros; es decir perteneciente a la raza hercúlea de los paladines, el último de los cuales fue; atribuyendo a este hecho una alta trascendencia, por cuanto nos vinculaba de un modo especialmente íntimo a la civilización greco-latina cuyos móviles fundamentales son la belleza y el individualismo. (18-9)

En esta declaración de principios, asumida por un enunciador desaprobado y, a pesar de todo, comprometido ("Yo declaré”), Lugones hace del payador Martín Fierro un prototipo, al igual que los héroes griegos. Aquí aparece solapada la “norma pagana”, una noción fundamental para comprender la filosofía de Lugones y su peculiar concepción esotérica de la creación literaria. En "Lugones, un helenista comprometido”, ya habíamos señalado la importancia de este concepto, ideado para establecer una filiación espiritual entre los héroes homéricos y los argentinos. Con esta norma, de cuño teosófico, justifica el autor los aportes literarios clásicos a la epopeya medieval mediante principios tales como la transmigración de las almas y la palingenesia. Aunque muy discutible, esa supuesta continuidad entre la Antigüedad, la Edad Media y la Revolución de Mayo pone de manifiesto el afán patriótico que motiva toda la obra de Lugones: el de acceder a los orígenes de la nación argentina, demostrando la perennidad de su cultura y la autenticidad de los valores de sus antepasados.

Valiéndonos de esta peculiar “norma pagana”, y sin descartar del todo la importancia del Modernismo -cuyas propuestas renovadoras determinan la estética y la riqueza léxica de la obra-, centraremos el presente estudio de La guerra gaucha (1905) en la recuperación por parte de Lugones de escenas del pasado criollo con fines nacionalistas. Nuestro propósito consistirá en recalcar los procedimientos narrativos y simbólicos utilizados por Lugones para convertir a Güemes, el caudillo salteño, en una figura de excelencia, digna de reconocimiento nacional. De acuerdo con la advertencia de Philippe Hamon "la ideología y su oficio de filtro se dan a conocer, pues, en el desajuste que existe entre un modelo elaborado, que sirve de norma, y lo dado" (14), intentaremos desentrañar los "efectos-ideológicos"2 de la prosa de Leopoldo Lugones. Por fin, averiguaremos el alcance ideológico del desajuste que existe entre el género gauchesco y La guerra gaucha. Pero, ante todo, esbocemos una definición del héroe nacional.

Desde el punto de vista léxico, el concepto de héroe resulta difícil de definir porque, según normas genéricas (epopeya, tragedia), textuales o socio-históricas, cobró distintos sentidos a lo largo del tiempo. Procedente del latín heros -tomado a su vez del griego hêrôs-, el vocablo sabio designaba a un semidiós o a un jefe militar ilustre. De uso casi nulo hasta fines del siglo xvi, el término empezó a designar a un "varón ilustre y grande, cuyas hazañas le hicieron digno de inmortal fama y memoria” (Diccionario crítico etimológico). Esta nueva acepción marca un cambio semántico de gran transcendencia,

${ }^{2}$ Philippe Hamon explica que "el efecto-ideológico en un texto (y no la ideología) pasa por la construcción y la puesta en escena estilística de aparatos normativos textuales incorporados al enunciado” (20, nuestra traducción). 
puesto que señala el paso de un campo religioso a uno más bien profano. Por otra parte, al otorgar un papel relevante al discurso literario, hace posible la paulatina y tardía introducción de la acepción “protagonista, personaje principal”. Emergen entonces nuevas formas de heroísmo y, por tanto, nuevas reglas de reconocimiento: la canonización de los santos es una de ella, otras son las gestas elaboradas para exaltar virtudes aristocráticas y sacralizar dinastías monárquicas.

Ora príncipe, ora gran hombre o jefe de vocación revolucionaria, el héroe moderno se distingue antes que nada por sus altas virtudes morales y su valiente compromiso para con la colectividad. De modo que, cualquiera que sea la elaboración discursiva de la figura puesta en escena, su heroísmo coincide con una brillante realización de sí mismo que lo eleva casi al rango de ser divino. Sin embargo, a diferencia de los héroes de la Antigüedad, quienes proceden de un pasado legendario -acrónico y fabuloso-, los héroes modernos inscriben el hecho heroico en una cronología histórica que da al relato de sus hazañas un valor no sólo descriptivo y verosímil, sino también ideológico y simbólico.

Si nos atenemos al proceso de transfiguración heroica sufrido por seres de excepción, comprendemos que, por su protagonismo civil y/o militar, el héroe toma parte en un proceso político bien determinado; participa en la formación o en la consolidación de una comunidad socio-política, involucrándose directamente en la fundación de un nuevo orden. A partir de entonces, entran en tela de juicio relaciones sociales y valores que rompen con los códigos socioculturales del antiguo régimen. Verdadera ingeniería política, este proceso se vuelve más representativo, quizá más democrático, en la medida en que la gente común puede identificarse con el héroe. Ya no se trata, pues, de ensalzar a un ser de noble estirpe, sino más bien de ennoblecer a quien supo encarnar las virtudes civiles que definen la identidad colectiva. De ahora en adelante, el único criterio de reconocimiento válido será entonces el de pertenecer a la comunidad, vale decir a la patria o la nación (Fabre 242).

Para sistematizar, veamos ahora qué imagen del héroe consigue forjar Lugones en $\mathrm{La}$ guerra gaucha. En la nota “Dos palabras” aclara su propósito sin dejar de mencionar el carácter nacional del tema escogido. No se propone ahondar en lo nacional, sino más bien ilustrar tiempos primordiales; sólo procura “dar una idea, lo más clara posible, de la lucha sostenida por montoneras y republiquetas contra los ejércitos españoles” (37). La autenticidad del proyecto épico radicaría en la puesta en escena de múltiples refriegas entre los realistas e independentistas. A su vez, la escenificación de la violenta represión realista, en el período que media entre 1814 y 1818, serviría para ensalzar a la nación, cuyo patético compromiso con la patria constituye un momento clave del proceso de emancipación rioplatense.

En este contexto, poco favorable además a la política centralista de Buenos Aires, la resistencia que se armó en la región de Salta resultaba ser un caso aparte. Conducidas por el caudillo local Martín Miguel de Güemes, un rico noble de cepa vasca, las milicias gauchas $^{3}$ tenían la especificidad de ser bien estructuradas militarmente: agrupadas en

\footnotetext{
${ }^{3}$ Armando Raúl Bazán señala que "ese ejército mayoritariamente compuesto de criollos y mestizos, incorporó también a negros esclavos, por aplicación de disposiciones nacionales dadas en mayo y junio de 1813 y otro decreto posterior del 24 de diciembre, que ordenaba el rescate de los esclavos
} 
escuadrones y batallones de acuerdo con la división administrativa de las provincias ${ }^{4}$ y la diversidad del medio. Entre 1814 y 1821 el pueblo en armas llevó a cabo una guerra de recursos y sorpresas para rechazar los ataques del ejército del general José de la Serna. A pesar del constante hostigamiento realista, consiguieron impedir siete invasiones a Salta. Hasta 1815, año en que el caudillo fue electo gobernador por el Cabildo de Salta, Buenos Aires dio respaldo oficial a las campañas de Güemes: "tanto en los nombramientos de jefes y oficiales y en la concesión de ascensos como al considerar que esa guerra era un servicio público que debía ser costeado por la tesorería nacional, al menos hasta donde llegaran sus recursos”, advierte Armando Raúl Bazán (197-8). De modo que el coronel, antaño cadete del Regimiento Fijo de Buenos Aires y destacado edecán de Liniers en la derrota de la segunda invasión inglesa (1807), colaboraba con el gobierno porteño. Le animaba un fuerte sentimiento patriótico que sabía comunicar a sus hombres y una “abnegada voluntad de cumplir la misión americana que San Martín le había asignado” (Bazán 206).

Este breve repaso histórico merece aclaraciones. Puede parecer inoportuno, en efecto, evocar hechos que el propio autor se niega rotundamente a recordar: "el libro carece de fechas, nombres y determinaciones geográficas; pues estando la guerra en cuestión narrada al detalle en nuestras historias, no habría podido adornarse con semejantes circunstancias aquellos episodios sin evidente abuso de ficción” (La guerra 37).

Sin embargo, pensamos que uno de los "efectos-ideológicos" que define La guerra gaucha reside en que Lugones quiere "glorificar” a Güemes sin escribir una novela histórica. Afirma: "La Guerra Gaucha no es una historia, aunque sean históricos su concepto y su fondo", advirtiendo asimismo que le sería fastidioso rendir homenaje a todos los caudillos que fueron parte en las guerras de independencia. Estas advertencias nos llevan a preguntarnos qué verdadero objetivo persigue Lugones. ¿Cómo puede el autor alabar la acción heroica de los caudillos, quienes poseen "todos mérito igual”, sin abusar de ficción ni hacer historia? ¿Cómo puede ser “fiel” y “verdadero” el relato dentro de los límites que le impone Lugones? En fin, ¿cómo se justifica la contradicción que existe entre el anonimato nivelador de La guerra gaucha y el individualismo de un Güemes, el “numen simbólico" (38) de la resistencia norteña?

Pensamos que la teosofía puede proporcionarnos algunas respuestas. Así, cuando la crítica literaria toma en cuenta la adscripción de Lugones a las doctrinas de Helena P. Blavatsky, suele mencionar su creencia en la reencarnación y la importancia de los arquetipos de verdad y belleza, de influencia platónica. En su estudio de Las limaduras de Hephaestos (1910), Jorge Monteleone resume la peculiar concepción de la labor poética explicando que:

el mecanismo subyacente entre el mundo -pensado como un Texto universal-y el texto poético, es el de la analogía. El poema constituye así un reflejo metafórico del mundo,

y premiaban a éstos con la libertad después de haber servido en el ejército. Así se formó el regimiento n 7 de Pardos y Morenos y sirvió para incorporarlos al ejército de Güemes” (199).

${ }^{4}$ Es de notar que, a principios del siglo xix, Salta era un amplio territorio "dividido luego, en 1814, para formar las provincias de Tucumán (con Tucumán, Catamarca y Santiago del Estero) y de Salta (con Salta, Jujuy, Tarija, Orán, y Santa María)” (Cornejo 81). 
mundo del Texto y, asimismo, una representación metonímica de esa totalidad. El circuito se completa cuando aparece el escriba y traductor privilegiado del Texto universal: el poeta. (167)

Desde nuestra perspectiva, parece útil insistir en la importancia que tiene la traducción no solo en la poética sino también en el pensamiento nacionalista de Lugones. Pensamos incluso que si Lugones se empeñó en traducir los poemas de Homero no fue porque dominase el griego antiguo (sus detractores insinuaban además que traducía la Ilíada y la Odisea sin conocerlo), sino más bien porque, de acuerdo con sus convicciones y su interés en el platonismo, deseaba traducir la realidad, pasando del mundo sensible al mundo de las ideas. De modo que, si nos fijamos en el sentido figurado de la palabra latina “traductor", podemos ver en Lugones un "traduitor”, una suerte de guía iniciado, que ambicionaría revelar a sus coetáneos el verdadero sentido de las conductas heroicas que determinaron la emergencia de una nueva nacionalidad.

Figura emblemática de La guerra gaucha, Martín Güemes es a la vez militar de carrera y caudillo, oficial nacional y gobernador de Salta. Supo defender al mismo tiempo intereses nacionales y provinciales, prefiriendo luchar por la independencia en vez de participar en la organización constitucional de la nación:

Así, mientras la patria se debatía por dentro, al par recortada sobre el patrón unitario de sus doctores y plasmada en el crisol de los motines por el instinto federal de su caudillaje; mientras la nacionalidad pretendía su destino en deshecha borrasca, los ejércitos de la Revolución, como otros tantos raudales escapados al apego de su montaña, perecían desterrados en su propio triunfo, sobre tierra extraña o calumniados en la propia, pero certificando de tal modo al porvenir una herencia de naciones. (La guerra 290-1)

Para rendirle homenaje, Lugones centra su relato en el aspecto castrense de su biografía. Sin embargo, es de notar que la glorificación del oficial se fundamenta en una notable ausencia corporal que viene compensada por la incorporación de numerosos soldados. A menudo, el narrador señala el número de gauchos desplegados en los distintos frentes (véase 143, 191 o 216), lo cual recalca la alta capacidad de Güemes para movilizar a la población congregándola en partidas volantes o en montoneras locales. El anonimato de la soldadesca, así como el de los oficiales, es otro medio para recordar la autoridad ejemplificada por el caudillo: planifica estrategias y dicta órdenes inapelables. En “Carga”, el narrador transcribe la postdata de una carta suya, dirigida a un cabo: “... debiendo usted contener esa columna a todo trance. Dios gde. a usted” (139). Con estas pocas palabras, irrumpe en el relato el mando de Güemes. Entregado por un chasque, el mensaje recuerda la relación jerarquizada que existe entre los caudillos gauchos y el coronel, implicando lógicamente relaciones de dependencia e inferioridad, así como el deber de sacrificar la vida por la patria. El poder de lo escrito se vuelve, por ende, escritura del poder. Y la voz de Güemes, la del poder absoluto.

Parece muy lógico que la jerarquía militar subordine entre sí los personajes de $L a$ guerra gaucha. Sin embargo, se puede observar que, si bien escasean los referentes históricos en la obra lugoniana, dominan en cambio referentes sociológicos que hacen que 
la heroicidad de Güemes, tal como la escenifica Lugones, solo sea posible dentro de los límites impuestos por supervivencias feudales. De modo que cuando el autor representa metafóricamente la guerra de emancipación como un verdadero cataclismo sísmico ("Baile”), que obra para romper definitivamente los lazos coloniales entre la metrópoli y sus colonias, le consta que los temblores no perjudican el orden social establecido. Pensamos incluso que los episodios de La guerra gaucha desempeñan un papel dinámico y taxonómico, cuya finalidad no es sino elaborar el prototipo del jefe supremo. Cada episodio se vuelve, pues, pretexto para ejemplificar virtudes y acciones heroicas, encabezadas sucesivamente por militares de carrera, caudillos gauchos o patrones de estancia. De manera paradójica, la estructura fragmentada de la obra favorece el despliegue de una serie de autoridades jerárquicas que participan de la construcción simbólica de la omnipotencia de Güemes.

Al nivel descriptivo, el tratamiento de la corporalidad de los patriotas hace patente la existencia de un sistema de valores externos a la obra que, acorde a las discriminaciones y los privilegios que fundamentaban las sociedades del antiguo régimen, establecen sutiles jerarquías entre las semblanzas de los rebeldes. En sus retratos de los gauchos, el narrador presta particular atención a sus cualidades exteriores (indumentaria, señas particulares, gestos). El cuerpo, la apariencia física de los paisanos norteños y sus artes específicas de baquianos, rastreadores, domadores o payadores se vuelven entonces un pretexto "gauchosófico" 5 que permite a Lugones documentar con erudición la personalidad de los jinetes y su entorno campesino. Aquellos valiosos rasgos etnográficos otorgan verosimilitud a la obra lugoniana; asimismo, inscriben el relato en tiempos heroicos cuya pretérita realidad no se puede poner en tela de juicio. Pero, aquí, solo interesa el tipo humano del paisano porque, si nos atenemos a los prejuicios del narrador, los gauchos no son de por sí ningún dechado: "No realizaban por cierto un ideal de hombre sino un tipo de varón”, afirma tras un largo y sórdido retrato físico de las partidas volantes (42).

En cambio, las semblanzas de los caudillos gauchos o de los oficiales -graduados de cabo, sargento o capitán-suelen ser más precisas, aunque el narrador no recurra sino a muy pocas descripciones físicas. En vez de contemplar sus cuerpos, formas de vivir o redes de sociabilidad, prefiere remitir a un pasado personal, cuya evocación sirve para distinguirlos del resto del ejército. La mención de su fama, del poder económico del que gozaban y demás datos biográficos le permiten ahondar en su personalidad, haciendo hincapié en cierta complejidad psicológica de la cual no se beneficia la soldadesca. Contrasta estos retratos con los de los gauchos, a menudo reducidos a sinécdoques, figuras semánticas de inclusión, que favorecen fenómenos simultáneos de substitución y de equivalencia. Así, por ejemplo, la sinécdoque "heroica chiripa” (235) -vale decir el heroísmo del rastreadorremite por analogía a todos los gauchos que sacrifican la vida por la patria.

En sus descripciones de los rasgos morales de los caudillos, el narrador distingue las consabidas dotes morales necesarias para su transfiguración heroica: los jefes comparten con sus hombres “instinto de horda” (127), "invisible tenacidad” (141), "heroica temeridad” (230), osadía e ingenio. Pero, se singularizan por sus aptitudes artísticas e intelectuales:

${ }^{5}$ Remito aquí a una de las categorías establecidas por el sociólogo uruguayo Daniel Vidart en su prólogo al libro El Gaucho de Fernando O. Assunçao, citado en Becco (11) 
suelen reunirse en consejos de guerra para preparar emboscadas y, después del combate, entretener a sus hombres con cuentos populares o hazañas militares ("Vivac"). Se da incluso el caso de un oficial culto, cuya carrera militar se confunde con la poesía. El narrador señala que "el capitán, como buen poeta, tenía algo de héroe y aun por tal se jactaba sosteniéndolo a sablazos” (66). Con este cotejo, queda idealizado el caudillo de guerra, convirtiéndose el mando suyo en una obra de arte. Luchar por la libertad produce, pues, emociones estéticas y afectivas muy parecidas a las proporcionadas por la poesía. De modo que el ideal patriótico, cuando no poético, permite a las montoneras superar el miedo y sublimar los últimos instantes: ante la muerte, el capitán y sus hombres “cantaban [...] su propio holocausto" (78).

De manera general, la personalidad del caudillo ejerce una fuerte influencia sobre los gauchos, produciendo por tanto cierto rebajamiento ontológico de los mismos. Multitud anónima, "turba gregal” regimentada a expensas suyas (46), son fundamentalmente de condición servil (40). Desde el primer capítulo, su suerte queda sometida a decisiones ajenas. Así, las más de las veces, se debe su incorporación a las montoneras a la iniciativa del patrón: "Sus esclavos, instruidos por oficiales patriotas, compartían la suerte de la montonera; y ella en persona se dio una vez de moquetes con cierta vecina que comadreaba su realismo, vistiendo hábito de la Purísima y peinándose a la izquierda” (“Artillería” 191). "Cacique, acudía por centésima vez con la flor de sus súbditos que llevaban cinco años de guerra, sin haber visto en ese lapso un arma de fuego” (“Táctica” 217).

Parecen a menudo carecer de voluntad propia, excepto quizá el rastreador cuando atacó a solas un regimiento español de unos cien hombres (235). Obedecen las órdenes sin que su jefe se las dé de manera explícita: "nunca mandaba directamente; imbuía más bien su coraje” (65). Incluso las interpretan instintivamente (284). Animados por un excepcional espíritu de sacrificio, los paisanos no tienen veleidades de rebelarse contra la arbitrariedad de un caudillo paternalista, aunque los lazos afectivos forjados los someten a una violencia desmesurada: "Ni se indignaban ni compadecían, tanto estupor les causaba aquello, tanto dominio ejercía sobre su voluntad el temido jefe” (51).

La figura del caudillo se destaca, pues, por su prestigio y su valor personal. Jefe y patriarca idolatrado, consigue canalizar emociones primitivas tales como el odio o el deseo de venganza, trocando los furores populares en heroísmo (89). Despierta una profunda admiración que, a su vez, se vuelve una fuerza estimulante, capaz de convertir en patriotismo el fuerte arraigo de los gauchos en la tierra, así como su odio hacia el rey y la administración virreinal: “detestaban al rey como a un patrón engreído y cargoso en la persona de sus alcaldes, bajo la especie de sus gabelas; persuadiéndolos más que un principio un instinto de libertad definido por las penurias soportadas” (41). Apoderándose del cariño de su gente, el caudillo puede entonces "preconiza[r] entre sus soldados locuras heroicas” (46).

En el caso de Güemes, esa fuerza es una “inspiración” (283), es decir, un impulso divino, una luz celeste, que comunica a los hombres un movimiento sobrenatural (Diccionario de autoridades). Al transmitir aquella inspiración, las palabras profesadas se aparentan al Logos. Impartiendo la orden absoluta de una victoria a todo trance (139 y 283), el jefe trascendería, pues, la realidad bélica, haciendo patente la tensión entre lo real y lo ideal. Irradiaría el aura del caudillo solar a todo el ejército, convirtiendo las 
refriegas en actos de bravura, pruebas de un heroísmo indefectible. Al nivel de los caudillos gauchos, las palabras transmiten idéntico impulso, mientras se vuelven un medium sagrado que manifiesta el Logos, fuente de las Ideas. Por su función reveladora vedan a los gauchos el acceso a toda forma de discurso. Así, en "Vado”, el patriotismo del Tontito de la Patria nació al oír las conversaciones de su patrón con los montoneros (174). El retrato del adolescente, un joven abyecto e inmaduro (172) despierta asco, pero, por caricaturesco que sea, da a entender que los humildes patriotas pueden elevar su espíritu con tal que sigan el liderazgo de un ser ideal y "superior”, como puede serlo un patrón o un caudillo. Aunque el episodio apoya la idea de que la guerra gaucha fue una empresa colectiva y solidaria, pensamos que se perfila aquí la “divergencia universal”, un concepto seudocientífico que le servirá a Lugones para denunciar a partir de 1912 prácticas democráticas.

Para entender mejor el proceso discriminatorio que supone este concepto, vale la pena recordar las concepciones teosóficas expuestas en las glosas de los Estudios helénicos. Así, en el "Discurso preliminar”, ${ }^{6}$ Lugones afirma que, por encarnar todas las virtudes aristocráticas, poéticas y militares, los héroes griegos o criollos son de la "raza de belleza”, raza sociocultural que concibe de la manera siguiente:

De mis lecturas históricas he sacado, efectivamente, una consecuencia que reputo interesante, y es: que la humanidad blanca hallase constituida por dos géneros de razas a las cuales impulsan dos móviles distintos e inconciliables hasta hoy, si no eternamente opuestos: los griegos, latinos y celtas, que son las razas de la belleza y del individualismo; los semitas, eslavos y germanos, que son las razas del colectivismo y de la verdad. (19)

A partir de este postulado, ${ }^{7}$ Lugones establece una jerarquía de valores que opone voluntad y destino, espiritualidad y materialidad y, por fin, individuo y multitud, haciendo coincidir caracteres biológicos con principios morales. Los valores espirituales que definen la "raza de belleza" -revelándose estos mediante obras de arte- garantizan el individualismo, la libertad y la igualdad de los hombres que la integran. A su vez, la "raza de verdad”, más dogmática, conduce al colectivismo. Concluye el cotejo advirtiendo:

Esto produce resultados sociales tan netos y diferentes, que su comprensión da la clave de la historia. Así, las razas de la belleza y del individualismo, lo son también de la libertad y de la igualdad; como las razas de la verdad y del colectivismo, lo son igualmente de la autoridad y de la jerarquía. (21)

Aunque muy problemático, interesa aquel planteo ideológico, ya que condiciona el proceso de transfiguración heroica de Güemes. En varias oportunidades, relaciona el autor

\footnotetext{
${ }^{6}$ Es de notar que este discurso inaugural, titulado al principio "El país de la belleza”, fue leído en el teatro Colón durante el acto inaugural del 14 de julio de 1916.

${ }^{7}$ A pesar de que el autor no cite explícitamente obras de autoridad para justificar su teoría, cabe señalar que tanto la obra Histoire philosophique du genre humain del esotérico francés Fabre d'Olivet como La Doctrina secreta de H. P. Blavatsky, ejercieron una influencia relevante en el pensamiento y la creación poética de Leopoldo Lugones. Véase Marini Palmieri.
} 
de manera muy clara la historia con una escala de principios y valores que fundamentan estrictas jerarquías entre los seres humanos, atribuyendo al héroe un estatuto de ser "superior" o de "hombre completo" (Nuevos estudios helénicos 41). Por otra parte, el distinguir dos razas entre la humanidad blanca excluye a ciertas minorías raciales que, por cierto, nunca tuvieron ascendencia latina, lo cual podría llevarnos a considerar el protagonismo de los gauchos de manera más polémica.

Sea lo que fuese, es de confesar que dicho esquema, si bien se trasluce a lo largo de los episodios de La guerra gaucha, no es del todo francamente reivindicado. En cambio, aparecen dicotomías que, por saturación simbólica, cumplen con el proyecto exclusivo de glorificar a Güemes. Así, en el último episodio de La guerra gaucha, la figura solar y radiante del héroe surge sumando todas las virtudes de los caudillos gauchos. La valentía y el albedrío de Güemes hace del personaje un ser ejemplar y carismático, reconocido por todos, incluso por sus contrarios. De tal suerte que, desde e1 prisma de un anteojo realista, su heroísmo se impone como una evidencia: “Alguien profirió un nombre entre los oficiales. El asombro aplacó los ceños. Pasó de mano en mano el anteojo. Por fin lo veían. En efecto, era él” (281).

El caudillo salteño encarna una voluntad todopoderosa, capaz de impulsar el móvil patriótico y comprometer definitivamente la dignidad de su gente en el desafío de su humanidad. En un momento fundador de la nación argentina, supo cambiar el curso de la historia e integrar la comunidad salteña en la incipiente colectividad nacional (286), simbolizada con toda lógica por el Sol de Mayo (292). El proceso de fabricación del héroe patrio parece culminar cuando el narrador equipara a Güemes con los Libertadores San Martín y Bolívar (291), otorgándole la misma trascendencia histórica. Así, por cumplir con los requisitos de la historiografía decimonónica que ensalzó la autoridad y el poder de los caudillos, el prototipo político-militar que forjó Lugones hace de la guerra gaucha un acontecimiento fundador en el que puede cristalizarse la conciencia colectiva. Sin embargo, cuando afirma el narrador: "San Martín lo prohijó. Desde comandante de campaña, mereció siempre su crédito, cobijado el aguilucho por el cóndor sagaz. Y no había fallado al linaje heroico” (290), no deja de llamar la atención la mención de un "linaje heroico” porque, más allá del respaldo estratégico e ideológico del general San Martín, anticipa la "progenie homérica” de los Estudios helénicos y la “norma pagana”, concebida por Lugones para arraigar la historia argentina en un continuum, cuyo punto de arranque sería la antigüedad. No cabe la menor duda de que dicha metáfora participa de la necesidad de “mitificar” los orígenes de la nación. Responde asimismo a la voluntad de entusiasmar a los lectores para que puedan identificarse con el prócer (Roux López 37). Pero al mismo tiempo, la intención programática que supone “no fallar al linaje heroico” indica que, en tanto jefe supremo, y de acuerdo con las doctrinas ocultistas profesadas por Lugones, Güemes supo respetar el orden inmutable que, desde siempre, fundamenta y legitima el gobierno de las élites. De ahí que la “intención épica” que domina la obra, no solo coincida con la búsqueda de una "forma capaz de transfigurar la materia histórica en leyenda nacional” (Gramuglio 159), sino que, en su reclamo por la tradición nacional, intente legitimar el poderío de la oligarquía argentina. A menudo criticados por su abundancia, los datos sociológicos facilitados a lo largo de la obra desempeñan una función ideológica 
que tiende, primero, a “nacionalizar” tanto el territorio como la solidaridad cívica y, luego, a rechazar la legitimidad de un poder basado en un principio mayoritario.

En La guerra gaucha Lugones pone en escena su propio imaginario político, en el cual se mezclan contenidos racionales (históricos) e imaginarios (míticos y simbólicos), para representar e institucionalizar una sociedad ideal, jerarquizada, en la que perdurarían antiguas relaciones patriarcales. Los episodios no son sino apologías de un gobierno representado como una especie de contrato entre dos grupos sociales que, voluntaria y libremente, se habrían repartido protagonismos políticos bien definidos: mandar u obedecer. En "La hora de la espada”, en momentos de conmemorar la batalla de Ayacucho (v. gr., la victoria final sobre el ejército del general de La Serna), Lugones se hará aun más explícito al afirmar:

El sistema constitucional del siglo xIX está caduco. El ejército es la última aristocracia, vale decir la última posibilidad de organización jerárquica que nos resta entre la disolución demagógica. Solo la virtud militar realiza en este momento histórico la vida superior que es belleza, esperanza y fuerza. (78)

Con esta cita, vemos que las relaciones verticales descritas en La guerra gaucha son prácticas políticas que no solo remiten a una sociedad colonial, cuyas bases venían determinadas por grupos sociales centrípetos y jerárquicos, sino también a una concepción reaccionaria de la comunidad nacional. Por eso, pensamos que en cierta medida la ficción participa ya del afán lugoniano de forjar una tradición nacional orientada, del cual da constancia toda su ensayística. Así pues, a partir de una figura histórica reconocida, ${ }^{8}$ Lugones da cuerpo a la nación argentina, haciendo del caudillo salteño la encarnación simbólica del territorio, del pueblo y de caracteres criollos. En tanto que héroe nacional, Güemes pasa a personificar una identidad colectiva todavía regida por principios excluyentes, de tinte aristocrático. Asimismo, es de advertir que la exaltación patriótica a la que se entrega Lugones tiene como correlato la valoración de un sistema guerrero que niega toda forma de participación cívica, en términos de libertad individual e igualdad, mientras implica sin distinción alguna disciplina, uniformidad y obediencia. En 1905, en un país en trance de democratización, la publicación de La guerra gaucha marca, a nuestro parecer, un hito más en el pensamiento nacionalista lugoniano puesto que el sacrificio último, por la patria, supone necesariamente las ideas de pureza moral y de arraigo en la Argentina, conceptos que anticipan el racismo historico-cultural -cuando no biológicoque, a partir de 1916, fundamentará su discurso nacionalista.

BiBLIOGRAFIA

Bazán, Armando Raúl. Historia del noroeste argentino. Buenos Aires: Plus Ultra, 1986 Becco, Horacio Jorge. Antología de la poesía gauchesca. Madrid: Aguilar, 1972.

Cornejo, Atilio. "Martín Güemes”. Cuaderno de sociología 4 (1965): 79-120

Corominas, Joan. Diccionario crítico etimológico de la lengua castellana. Berna:

Francke, 1979

${ }^{8}$ En 1902, salió el primer tomo del notable estudio Historia del Gral. Güemes y de la Provincia de Salta de Bernardo Frías. 
Fabre, Daniel. “L’atelier des héros”. La fabrique des héros. Dir. de P. Centlivres, D. Fabre, F. Zonabend. Paris: Maison des Sciences de l'Homme - Mission du Patrimoine ethnologique, 1999. 233-318

Fürsenberger Nathalie. "Lugones, un helenista comprometido”. Río de la Plata 20-21 (2000): 255-65.

Gramuglio, María Teresa. “La primera épica de Lugones”. Prismas 1 (1997): 157-63.

Hamon, Philippe. Texte et idéologie. Paris: P.U.F., 1997.

Lugones, Leopoldo. La hora de la espada y otros escritos. Buenos Aires: Perfil, 1998. La guerra gaucha. Buenos Aires: Losada, 1992.

Obras poéticas completas. 2 ed. Madrid: Aguilar, 1952. Nuevos estudios helénicos. Buenos Aires: Babel, 1928. Estudios helénicos. Buenos Aires: Babel, 1923-1924.

Marini Palmieri, Enrique. “L’occultism militant dans le modernisme de Leopoldo Lugones”. Création littéraire et traditions ésotériques. ( $X V$ - $X X$ siècles). Faculté des Lettres et Sciences Humaines de Pau et des Pays de l’Adour. J\&D Eds., 1991. 237 44.

Monteleone, Jorge. “Lugones: canto natal del héroe”. Yrigoyen entre Borges y Arlt (19161930). Buenos Aires: Contrapunto, 1989.

Real Academia Española. Diccionario de autoridades. Madrid: Gredos, 1963.

Roux López, Rodolfo de. “La insolente longevidad del héroe patrio”. Caravelle 72 (1999): 31-43. 